\title{
Lomber Diskopati Tanılı Olgulara Uyguladığımız Epidural Kortikosteroid Enjeksiyonunun Klinik Sonuçları
}

\author{
Jülide Öncü' ${ }^{1}$ Reşat illişer ${ }^{1}$, Göksel Çelebi', Banu Kuran¹, Gülgün Durlanık1
}

\begin{abstract}
ÖZET:
Lomber diskopati tanılı olgulara uyguladığımız epidural kortikosteroid enjeksiyonunun klinik sonuçları

Amaç: Lomber epidural steroid enjeksiyonları (LESE) lomber disk hernisinde (LDH) kullanılan minimal invaziv tedavi yöntemleridir. Bu çalışmada, konservatif tedavi yöntemleri ya da cerrahi tedaviyle iyileşmeyen bel ağrısı şikayeti olan hastalara uyguladığımız LESE tedavisinin, semptomlar ve yaşam kalitesine etkisini incelemeyi amaçladık.

Gereç ve Yöntem: Çalışma, kliniğimize konservatif tedaviye dirençli lomber diskopati tanısı olan 37 hastaya uygulanan LESE (transforaminal (TF), kaudal (K), interlaminar (iL)) kayıtlarının retrospektif olarak incelenmesi ile gerçekleştirildi. Ağrı şiddeti Vizüel Analog Skala (VAS) ile, sinir germe delilleri düz bacak kaldırma (DBK), dizabilite düzeyleri Oswestry Dizabilite İndeksi (ODI), yaşam kalitesi ise SF-36 ile ilk 24. saat, 1 .hafta, 1 . ay ve 3 . ayda değerlendirildi.

Bulgular: VAS-radiküler ağrı düzeylerinde, ilk 24. saatte $(p<0.01), 1$. haftada $(p<0.01), 1$. ay $(p<0.01)$ ve 3.ayda ( $p<0.05)$ istatistiksel olarak anlamlı iyileşme mevcuttur. VAS-lomber ağrı düzeylerinde, ilk 24.saatte $(p<0.01), 1$. haftada $(p<0.01), 1$. ay $(p<0.05)$ ve 3.ayda $(p<0.05)$ istatistiksel olarak anlamlı iyileşme mevcuttur. ODI düzeylerinde ve SF-36 ile değerlendirilen yaşam kalitesinde ise tedavi öncesine göre ilk 24.saatte ( $p<0.01), 1$. haftada $(p<0.01), 1$. ay $(p<0.01)$ ve 3.ayda $(p<0.05)$ istatistiksel olarak anlamlı iyileşme mevcuttur.

Sonuç: Minimal invaziv bir yöntem olan LESE tedavisinin LDH tanısı olan hastalara uygulanmasıyla başarılı sonuçlara ulaşabileceğimiz kanaatindeyiz.

Anahtar kelimeler: Radikülopati, epidural steroid enjeksiyonu, bel ağrısı
\end{abstract}

\section{ABSTRACT:}

Efficacy of lumbar epidural corticosteroid injections on clinical status of the patients with radiculopathy

Objective: To investigate the effect of lumbar epidural steroid injection in patients with radiculopathy Materials-Methods: 37 patients with radiculopathy were recruited retrospectively in the study.

Radicular, low back pain and paresthesia intensity were evaluated using visual analog scale (VAS); the evidence of nerve stretch was evaluated by straight leg rising (SRL), disability levels were evaluated using the Oswestry Disability Index (ODI) and the quality of life was evaluated by SF-36.

Results: A significant improvement was observed in VAS-radicular and lomber pain levels at the $24^{\text {th }}$ hours post-injection ( $\left.p<0.01\right)$, at the $1^{\text {st }}$ week $(p<0.01)$, at $1^{\text {st }}$ month $(p<0.01)$ and $3^{\text {rd }}$ month $(p<0.05)$. Recovery rate of straight leg raising test was found to be $88 \%$ ( $p<0.05$ ). A statistically significant improvement was found in the ODI levels and the quality of life as assessed by the SF-36 at the1st week $(p<0.01)$ and after 3 months of the treatment $(p<0.05)$.

Conclusion: During the first 3 months of treatment, lumbar epidural corticosteroid injections were effective in patients with radiculopathy

Key words: Radiculopathy, epidural steroid injections, low back pain

Ş.E.E.A.H. Tıp Bülteni 2014;48(1):34-8
'Sişli Hamidiye Etfal Eğitim ve Arastırma Hastanesi, Fizik Tedavi ve Rehabilitasyon Kliniği, İstanbul-Türkiye

Yazısma Adresi / Address reprint requests to: Jülide Öncü, Şişli Hamidiye Etfal Eğitim ve Araştırma Hastanesi, Fizik Tedavi ve Rehabilitasyon Kliniği, İstanbul-Türkiye

\section{E-posta / E-mail:} julideoncu@yahoo.com

Geliş tarihi / Date of receipt: 23 Ocak 2014 / January 23, 2014

Kabul tarihi / Date of acceptance: 06 Şubat 2014 / February 06, 2014 


\section{Giriş}

Günümüzün ciddi tıbbi ve sosyoekonomik sorunlarından biri bel ağrısı ve ağrıya eşlik eden radiküler semptomlardır (1). Hastaların yarısından fazlasının sosyal yaşamlarında ciddi kısıtlamalara yol açan bu tablonun bilinen en sık nedenleri arasında lomber disk herniyasyonları gelmektedir (2).

Bu klinik durumda ortaya çıkan semptomların ise medikal tedavi (antienflamatuvar ilaçlar, kas gevşeticiler, opioidler, antidepresanlar), fizik tedavi uygulamaları ve korse uygulaması gibi konservatif tedavi yöntemleri ile büyük oranda iyileştiği bilinmektedir $(3,4)$. Konservatif tedavi yöntemleriyle sonuç alınamayan hastalarda epidural steroid enjeksiyonları alternatif tedavi yöntemleridir (5).

Epidural enjeksiyonların bel ağrılarının tedavisinde ilk olarak kullanımı 1930 yılında Evans tarafından tanımlanmıştır (6). Lomber epidural steroid enjeksiyonu (LESE), floroskopik rehberlik altında, radikulopatik bel ağrılarına etkili olan farklı bir tedavi yaklaşımı olarak tarif edilmektedir (7-11).

Bu çalışmada, konservatif tedavi yöntemleri ya da cerrahi tedaviyle iyileşmeyen bel ağrısı şikayeti olan hastalara uyguladığımız LESE tedavisinin etkinliğini retrospektif olarak incelemeyi amaçladık.

\section{GEREÇ VE YÖNTEM}

Çalışma verileri Ekim- 2011 - Mart-2013 arasındaki dönemde, yaşları 20-80 arasında değişen, LDH nedeniyle LES enjeksiyonu tedavisi uygulanan 37 hastanın dosya bilgilerinden elde edildi. Çalışma, Fiziksel Tıp ve Rehabilitasyon Kliniği'ne lomber disk hernisi (LDH) tanısı nedeniyle yatırılarak, 14 seans fizik tedavi (Sıcak paket (20 dk/gün), Transkutanöz Elektriksel Stimülasyon (100 Hz, 20 dk/gün), ultrason (1Mhz; $0.8 \mathrm{w} / \mathrm{cm}^{2} ; 10 \mathrm{dk} /$ gün) uygulaması sonrası yarar görmeyen ve LES enjeksiyonu uygulanan hastalara ait kayıtların retrospektif olarak incelenmesi ile gerçekleştirildi.

Hastalara poliklinik koşullarında anamnez, fizik muayene ve görüntüleme yöntemleriyle LDH tanısı konulmuştur. Hastaların yaşı, cinsiyeti, bel ve bacak ağrısı şikayetlerinin süresi ve şiddeti sorgulanarak, şiddeti Vizüel Analog Skala (VAS) ile değerlendirildi.
Bel ağrısı VAS-bel, radiküler ağrı şiddeti VASradiküler olarak belirtildi. VAS, hastaların hiç ağrının olmadığı "O" ve hissettiği ağrının en şiddetli olduğu noktanın "100" olarak gösterildiği horizontal bir çizginin üzerinde işaretleme yapmaları sonucu oluşturulmaktadır. Fonksiyonel düzey Oswestry Dizabilite İndeksi ile değerlendirilmiştir (12). Oswestry sakatlık skoru; hastanın on aktivitedeki performans kısıtlılığını altı puanlık skalada (0-5) değerlendiren bir indekstir. Bu skalaların toplanması ile maksimum skor olarak 50 puan elde edilir; skor artımı fonksiyonel kısıtlılık artışını ifade etmektedir (12).

Yaşam kalitesi ise, SF-36 ile değerlendirilmiştir. Tıbbi alanda en sık kullanılan jenerik yaşam kalitesi ölçeği olup fiziksel ve mental yönden sağlığı değerlendiren toplam 36 maddelik 8 alt skaladan oluşmaktadır (13). Bu alt skalalar, fiziksel fonksiyon, fiziksel yönden rol kısıtlılığı, ağrı, genel sağlık, yaşamsallık, sosyal fonksiyon, emosyonel yönden rol kısıtlılığı ve mental sağlıktır (13). Türk toplumu için uyarlanması yapılmış ve osteoartrit ve kronik bel ağrılı hastalarda geçerli ve güvenilir bulunmuştur (13).

Kliniğimizde yatarak fizik tedavi ve medikal tedavi uygulanan (konvansiyonel tedavi), ancak iyileşmeyen ve VAS skoru 6 ve üzerinde olan hastalara LES enjeksiyonu uygulanmasına karar verilmektedir. LES enjeksiyonu yapılacak olgulara tedavi detaylı olarak anlatılmakta, aydınlatılmış onamları sözlü ve yazılı olarak alınmaktadır.

Hastalara periferik damar yolu açılması sonrası elektrokardiyografi, puls oksimetre ve arteriyel kan basıncı monitorizasyonu uygulanmaktadır. Hastalar pron pozisyona getirilip steril örtülmektedir. Cilt altı ve derin dokulara lokal anestezik olarak lidokain 1 $\mathrm{mg} / \mathrm{kg}$ dozunda uygulanmaktadır. Spinal 22G iğne uygulama seviyesine $\mathrm{C}$ kollu floroskopi cihazı rehberliğinde yönlendirilmektedir. Kaudal (sakral hiatustan) veya interlaminar (o seviyede laminalar arasından) yöntemle girildiğinde epidural alana, transforaminal yöntemle (nöral foramene) girildiğinde ise vertebral foramene ulaşıldığı, opak maddenin (Omnipaque 300R) sinir köküne ve özellikle anterior epidural alana yayılımı floroskopi ile görülerek ispatlanmaktadır. Daha sonra 40 mg triamsinolon heksasetonid transforaminal ve interlaminar epidural; $80 \mathrm{mg}$ triamsinolon heksasetonid $15 \mathrm{ml}$ 0.9\% serum fizyo- 
lojik ile beraber kaudal epidural yöntemle floroskopi altında kontrast madde eşliğinde uygulanmıştır.

İşlem sonrası hastalar 24 saat komplikasyonlar yönünden takip edilmektedir. Hastaların 24 saat sonra kontrolünde ağrı düzeyleri VAS skoru ile, dizabilite Oswestry Dizabilite İndeksi (ODi) ile, yaşam kalitesi SF-36 ile tekrar değerlendirilerek kaydedilmektedir. Birinci hafta, 1 . ay ve 3 . ayda ise poliklinik kontrolüne çağırılarak hastalar tekrar kontrol edilmektedir. Böylece kayıtlarda hastaların tedavi öncesi (VASTÖ), 24.saat (VAS-24.saat), 1. ay (VAS-1.ay) ve 3. ay (VAS-3.ay) değerleri ile aynı şekilde ODI, SF-36 skorları bulunur.

\section{İstatistiksel Analiz}

SPSS 13.0 programı ile yapıldı. Sonuçlar ortalama ve Standard sapma ve yüzde olarak verildi. Klinik değerlendirme (VAS; ODI; SF-36) skorları arasındaki fark Wilcoxon testi ile; takip süreleri arasındaki fark ise örneklem t-testi ile incelendi. $P$ değerinin $<0.05$ olması istatistiksel olarak anlamlı kabul edildi.

\section{BULGULAR}

Yaşları 20-80 arasında olan, daha önce LDH nedeniyle opere olmamış, konservatif tedaviye dirençli, en az 3 aydır LDH tanısı bulunan hasta çalışmaya alınmıştır. Hastaların demografik verileri ile tedavi öncesi klinik değerleri Tablo 1'de özetlenmiştir. $32 \mathrm{LDH}$ tanılı hastanın 12'sine 40 mg triamsinolon heksasetonid transforaminal epidural; 12 'sine $80 \mathrm{mg}$ triamsinolon heksasetonid $15 \mathrm{ml} 0.9 \%$ serum fizyolojik ile beraber kaudal epidural; 8' ine de $40 \mathrm{mg}$ triamsinolon heksasetonid interlaminar epidural yön- temle floroskopi altında kontrast madde eşliğinde uygulanmıştır.

Tedavi öncesi, 24.saat, 1.hafta, 1.ve 3. ay klinik parametreler arasındaki istatistiksel farklar Tablo2 'de özetlenmiştir. Grubun tamamında enjeksiyon sonrası ilk 24 saatte değerlendirilen VAS-radikuler ağrı düzeylerinde istatistiksel anlamlı iyileşme mevcuttur $(p<0.01)$, iyileşme oranı \%82 olarak saptanmıştır. VAS ile değerlendirilen bel ağrısı düzeylerinde tedavi öncesine göre istatistiksel anlamlı iyileşme mevcuttur $(p<0.05)$; iyileşme oranları \%75 olarak saptanmıştır. DBK testlerinde iyileşme oranı \%88 olarak bulunmuştur $(p<0.05)$. ODI düzeylerinde ve SF-36 ile değerlendirilen yaşam kalitesinde ise tedavi öncesine göre ilk 24.saatte istatistiksel olarak anlamIı iyileşme mevcuttur $(p<0.01)$ (Tablo 2).

1. haftada VAS-radiküler ağrı düzeylerinde tedavi öncesine göre istatistiksel anlamlı iyileşme mevcuttur $(p<0.01)$, iyileşme oranı \%80 olarak saptanmıştır. VAS ile değerlendirilen bel ağrısı düzeylerinde tedavi öncesine göre istatistiksel anlamlı iyileşme mevcuttur ( $p<0.05)$; iyileşme oranları \%72 olarak saptanmıştır. DBK testlerinde iyileşme oranı \%86 olarak

Tablo 1: Hastaların klinik ve demografik özellikleri $(n=37)$

$\begin{array}{ll}\text { Yaş (yıl } \pm \text { SS) } & 43.2 \pm 20.9 \\ \text { Cinsiyet (K/E) (n) } & 16 / 15 \\ \text { Medeni durum (evli) (\%) } & 86 \\ \text { Hastalı süresi (ay } \pm \text { SS) } & 7.4 \pm 2.5 \\ \text { VAS-lomber (cm) (ort } \pm S S) & 100 \pm 1.5 \\ \text { VAS-radiküler (cm) (ort } \pm S S) & 100 \pm 1.8 \\ \text { DBK testi pozitifliği (\%) } & 55 \\ \text { ODI skoru (ort } \pm S S) & 37.9 \pm 12.1 \\ \text { SF-36 skoru (ort } \pm S S) & 22.4 \pm 10.1\end{array}$

SS: Standard sapma, Ort: Ortalama, VAS: Vizüel analog skala,

ODI: Oswestry Dizabilite İndeksi, DBK: Düz bacak kaldırma testi, K: Kadın, E: Erkek.

Tablo 2: Klinik verilerin enjeksiyon sonrası takipleri

\begin{tabular}{llllll}
\hline & Enjeksiyon öncesi & 24.saat & 1.hafta & 1.ay & 3.ay \\
\hline VAS-lomber (cm) (ort \pm SS) & $100 \pm 1.5^{*,+, \neq}$ & $10.5 \pm 0.7$ & $22.5 \pm 0.8$ & $24.7 \pm 0.9$ & $38.6 \pm 10.0$ \\
VAS-radiküler (cm) (ort \pm SS) & $100 \pm 1.8^{*,+, \neq}$ & $13.4 \pm 0.9$ & $24.1 \pm 0.7$ & $25.8 \pm 10.1$ & $39.3 \pm 15.6$ \\
DBK testinde iyileşme oranı(\%) & $82^{*,+, \neq}$ & 86 & 88 & 85 & 83 \\
ODI skoru (ort \pm SS) & $37.9 \pm 12.1^{\S}$ & $15.4 \pm 5.1$ & $18.9 \pm 8.2$ & $19.2 \pm 9.0$ & $18.1 \pm 5.8$ \\
SF-36 skoru & $22.4 \pm 10.1^{11}$ & $40.6 \pm 10.5$ & $45.1 \pm 10.1$ & $44.3 \pm 12.2$ & $42.3 \pm 13.1$ \\
\hline
\end{tabular}

*: Enjeksiyon öncesi ve 24. saatte VAS değerleri arasındaki istatistiksel anlamlı farklılık ( $<<0.01$ ), t: Enjeksiyon öncesi ve ilk haftadaki VAS değerleri arasındaki istatistiksel anlamlı farklııı ( $p<0.01$ ), ‡: Enjeksiyon öncesi ve 1.haftadaki VAS değerleri arasındaki istatistiksel anlamlı farklılık (p<0.01), §: Enjeksiyon öncesi ve enjeksiyon sonrası tüm ODI skorları arasındaki istatistiksel anlamlı farkılık (p<0.05), Il: Enjeksiyon öncesi ve enjeksiyon sonrası tüm SF-36 skorları arasındaki istatistiksel anlamlı farklılık (p<0.05). SS: Standard sapma, Ort: Ortalama, VAS: Vizüel analog skala, ODI: Oswestry Dizabilite İndeksi, DBK: Düz bacak kaldırma testi 
bulunmuştur $(p<0.05)$. ODI düzeylerinde ve SF-36 ile değerlendirilen yaşam kalitesinde ise tedavi öncesine istatistiksel olarak anlamlı iyileşme mevcuttur $(\mathrm{p}<0.01)$ (Tablo 2).

Birinci ay ve 3.ayda ise sırasıyla VAS-radiküler ağrı düzeylerinde istatistiksel anlamlı iyileşme mevcuttur $(p<0.01 ; p<0.05)$, iyileşme oranı $\% 80$ ve $\% 76$ olarak saptanmıştır. VAS ile değerlendirilen bel ağrısı düzeylerinde tedavi öncesine göre istatistiksel anlamIı iyileşme mevcuttur ( $p<0.05 ; p<0.05)$; iyileşme oranları \%73 ve \%74 olarak saptanmıştır. DBK testlerinde iyileşme oranları sırasıyla \%85 ve $83 \%$ olarak bulunmuştur $(p<0.05 ; p<0.05)$. ODI düzeylerinde ve SF-36 ile değerlendirilen yaşam kalitesinde ise tedavi öncesine göre 1 ve 3 . ayda istatistiksel olarak anlamIı iyileşme mevcuttur ( $p<0.01 ; p<0.05)$ (Tablo 2).

Hiçbir hastada işlemle ilgili herhangi bir komplikasyon saptanmamıştır.

\section{TARTIŞMA}

Çalışmamızın sonuçları, skopi altında uygulanan LES enjeksiyonlarının, ilk günden itibaren 3 aylık dönem boyunca ağrı, fonksiyon ve yaşam kalitesine olumlu etkilerinin olduğunu göstermektedir.

Günümüzde mekanik kompresyonun tek başına etkili olmadığı, radiküler semptomların gelişmesinde rol oynayan en önemli faktörün sinir kökündeki inflamasyon olduğu bilinmektedir (14). Lindblom (15), herniye diskin uzun süreli kompresyonuyla sinir köklerinde patolojik değişikliklerin geliştiğini göstermiştir. Buna karşın diğer araştırmacılar siyataljisi olmayan hastaların otopsilerinde $\% 40$ oranında herniye disk saptamışlardır. Ayrıca normal hastaların \%35'inde miyelografide patolojik bulgular gösterilmiştir (16). MRG yapılan asemptomatik hastaların \%60'ında disk hernisi saptanmıştır (16). Lindahl ve ark. (17), disk hernisi nedeniyle ameliyat edilen 10 hastanin 7 'sinde arka köklerden aldığı biopsilerde inflamasyon, ödem ve dejeneratif değişiklikler saptamıştır. Bu bulgular ışı ğında, selektif olarak perkütan yolla yüksek konsantrasyonda verilen steroid sinir kökü ve disk çevresindeki inflamasyonu azaltarak semptomların giderilmesinde etkili olmaktadır (18).

Çalışmamızda ağrı şiddetindeki iyileşme oranları- na bakıldığında, VAS-radiküler ağrı düzeyinde \%76, VAS-lomber bölge ağrı şiddetinde \%74 azalma olduğu ve bu iyileşmenin istatistiksel olarak anlamlı olduğu görülmüştür. Literatürde tıpkı bizim çalışmamızda olduğu gibi, ağrı şiddetinde belli oranlarda azalma olduğu bildirilmiştir $(18,19)$. Botwin ve ark. (19) skopi eşliğinde transforaminal epidural steroid enjeksiyonu sonrası hastaların GAS skorlarını değerlendirmişler ve 34 hastada \%75 oranında başarılı sonuç bildirmişlerdir. Ayrıca, ağrının en az \%50 oranında gerilediği görülmüştür. Başka bir çalışmada ise, iki ayrı tedavi grubundaki 48 hastada başarı oranı transforaminal epidural steroid enjeksiyonu yapılan grupta \%84 olduğu bulunmuştur (20).

Çalışmamızda görsel analog skala ile değerlendirilen ağrı skorlarında ilk 24. saatten itibaren klinik düzelme saptanmıştır ve bu düzelme ilk 24. saat ile 1. ayda; 3. aydakinden daha belirgindir. Yani enjeksiyonun etkisi ilk ayda çok belirgin olup, 3.aya kadar bir miktar azalarak devam etmekte ve klinik düzelme anlamlılı̆̆ını korumaktadır. Benzer şekilde LES enjeksiyonlarının erken dönemde etkin olduğuna dair literatürde veriler mevcuttur (21). Abdi ve ark. (21) lumbar ES enjeksiyonları uygulamasının etkinliğini 6 haftaya kadar iyi, 6 haftadan sonra orta derecede yararlı olarak tanımlamaktadır. Etkinlik açısından 6 aya kadar lumbar ES enjeksiyonları uygulaması 4 randomize kontrollü klinik çalışmada etkili olduğu bildirilmiştir $(22,23)$. Atım ve ark. (24) olgularında ilk 3. haftalık erken dönemden 6. aya kadar olan dönem boyunca LES enjeksiyonlarının etkili olduğunu bildirmişlerdir. Ağrının \%50 ve daha fazla düşürülmesi başarılı kabul edilip tüm hasta grupları göz önüne alındığında VAS-0'a göre VAS-3HF'da \%84 başarı, VAS-6AY'da \%78 başarı elde edilmiştir.

Biz de çalışmamızda ilk 3 aylık dönemde enjeksiyonların etkili olduğunu saptadık.

Bel ağrısı tedavisi için LESE'nin başarısızlığı deneyimli ellerde bile \%30 kadar yüksek derecede olabildiği bildirilmektedir (25). Herhangi bir görüntüleme yöntemi kullanılmadan, epidural steroid enjeksiyonlarının körlemesine yapıldığı çalışmalarda, yanlış yere enjeksiyon yapılma oranları kaudal teknikte $\% 40$, interlaminar teknikte \%30 civarında bildirilmiştir (25). Gerek interlaminar gerekse kaudal enjeksiyonlarda skopi kullanılmasının, iğnenin doğru yere 
yerleştirilmesinde yararlı olduğu saptanmıştır. Bu nedenle bizim kliniğimizde de hastalarımızda enjeksiyon yaparken C kollu skopi görüntüleme yöntemi olarak seçilmiştir.

LESE işlemine bağlı yan etki ve komplikasyon oranı literaturde \%7 civarında bildirilmiştir (18). Bunlar, artan ağrı, kas spazmı, baş ağrısı, minor kanama, baş dönmesi, bulantı/kusma, ateş, uyuşukluk, zorlu işeme, vazovagal tepki, motor güçsüzlük ve uykusuzluktur (18). Bizim kayıtlarımızda herhangi bir komp-

\section{KAYNAKLAR}

1. Weinstein SM, Herring SA. NASS. Lumbar epidural steroid injections. Spine J 2003; 3(3 Suppl): S37-S44.

2. Heliovaara $M, K n e k t P$, Aromaa A. Incidence and risk factors of herniated lumbar intervertebral disc or sciatica leading to hospitalization. J Chronic Dis 1987; 40: 251-8.

3. Bush K, Cowan N, Katz DE, Gishen P. The natural history of sciatica associated with disc pathology. A prospective study with clinical and independent radiologic follow-up. Spine 1992; 17: 1205-12.

4. Saal JA, Saal JS. Nonoperative treatment of herniated lumbar intervertebral disc with radiculopathy. An outcome study. Spine (Phila Pa 1976) 1989; 14: 431-7.

5. Lutz GE, Vad VB, Wisneski RJ. Fluoroscopic transforaminal lumbar epidural steroids: an outcome study. Arch Phys Med Rehabil 1998; 79: 1362-6.

6. Evans W. Intrasacral epidural injection in the treatment of sciatica. Lancet 1930; 2: 1225-9.

7. Lee JW, Kim SH, Lee IS, Choi JA, Choi JY, Hong SH, et al. Therapeutic effect and outcome predictors of sciatica treated using transforaminal epidural steroid injection. AJR Am J Roentgenol 2006; 187: 1427-31.

8. Lee JW, Kim SH, Choi JY, Yeom JS, Kim KJ, Chung SK, et al. Transforaminal epidural steroid injection for lumbosacral radiculopathy: preganglionic versus conventional approach. Korean J Radiol 2006; 7: 139-44.

9. Vad VB, Bhat AL, Lutz GE, Cammisa F. Transforaminal epidural steroid injections in lumbosacral radiculopathy: a prospective randomized study. Spine (Phila Pa 1976) 2002; 27: 11-6.

10. Gajraj NM. Selective nerve root blocks for low back pain and radiculopathy. Reg Anesth Pain Med 2004; 29: 243-56.

11. Sitzman BT. Epidural injections. In: Fenton DS, and Czervionke LF (eds). Image-guided spine intervention. Philadelphia: Saunders; 2003. s 99-126.

12. Hudson-Cook N, Tomes Nicholson K, Breen A. A revised Oswestry Disability Questionnaire. In: Roland MO, and Jenner JR (eds). Back pain. Manchester, Manchester University, 1989; s187-204.

13. Koçyiğit H, Aydemir Ö, Fişek G, Ölmez N, Memiş A. Kısa Form36 (KF-36)'nın Türkçe versiyonunun güvenilirliği ve geçerliliği. Romatizmal hastalığı olan bir grup hasta ile çalışma. Ilaç ve Tedavi Dergisi 1999; 12: 102-6. likasyon bilgisi tespit edilmemiş̧ir.

Sonuç olarak çalışmamızda, özellikle radiküler ağrısı olan hastalara skopi eşliğinde yapılan lomber epidural steroid ve lokal anestetik enjeksiyonunun, ağrı, fonksiyon ve yaşam kalitesine olumlu etkisinin olduğu gözlenmiştir. Komplikasyon saptanmadığı için güvenilir olduğu da saptanmıştır. Bu sonuçlar, uygulanan tedavinin kısa dönemde olduğu gibi ilk 3 aylık orta dönemde de etkinliğini devam ettirdiğini düşündürmektedir.

14. Brown FW. Management of discojenic pain using epidural and intrathecal steroids. Clin Orthop 1977; 129: 72-8.

15. Lindblom, K. Diagnostic puncture of intervertebral discs in sciatica. Acta orthop scand1948; 17: 231-9.

16. Catchlove RHV, Braha R: The use of cervical epidural nerve blocks in the manegement of chronic head and neck pain. Can Anaesth Soc J 1984; 31: 188-191.

17. O Lindahl, Rexed B. Histologic changes in spinal nerve roots of operated cases of sciatica - Acta Orthopaedica, 1951; 20; 21525.

18. Manchikanti L, Datta $S$, Gupta $S$, Munglani $R$, Bryce DA, Ward $S P$, et al. A critical review of the American Pain Society clinical practice guidelines for interventional techniques: part 2. Therapeutic interventions. Pain Physician 2010;13: E215-64.

19. Botwin KP, Gruber RD, Bouchlas CG, et al. Fluoroscopically guided lumbar transformational epidural steroid injections in degenerative lumbar stenosis: an outcome study. Am J Phys Med Rehabil 2002; 81: 898-905.

20. Vad VB, Bhat AL, Lutz GE, Cammisa F. Transforaminal epidural steroid injections in lumbosacral radiculopathy: a prospective randomized study. Spine (Phila Pa 1976) 2002; 27:11-6.

21. Abdi S, Datta S, Trescot AM, Schultz DM, Adlaka R, Atluri SL, Smith HS, Manchikanti L. Epidural steroids in the management of chronic spinal pain: a systematic review. Pain Physician 2007; 10: 185-212.

22. Riew KD, Park JB, Cho YS, Gilula L, Patel A, Lenke LG, et al. Nerve root blocks in the treatment of lumbar radicular pain. $A$ minimum five-year follow-up. J Bone Joint Surg Am 2006; 88: 1722-5.

23. Jeong HS, Lee JW, Kim SH, Myung JS, Kim JH, Kang HS. Effectiveness of transforaminal epidural steroid injection by using a preganglionic approach: a prospective randomized controlled study. Radiology 2007; 245: 584-90.

24. Atım A, Deniz S, Kılıçkaya O, Orhan M, Purtuloğlu P. Terapotik lomber transforaminal epidural steroid enjeksiyonu uygulamasının etkinliğinin değerlendirilmesi AĞRI 2011; 23: 114-8.

25. Manchikanti L. Transforaminal lumbar epidural steroid injections. Pain Physician 2000; 3: 374-98. 